\title{
Observations on the diet and behaviour of captive Monodelphis (Mygalodelphys) kunsi Pine, 1975 (Didelphimorphia: Didelphidae) from Paraguay
}

\author{
Helen Pheasey \\ Fundación Para La Tierra, Centro IDEAL, Mariscal Estigarribia 321 c/ Tte. Capurro, Pilar, Dpto. Ñeembucú, Paraguay, \\ www.paralatierra.org, paralatierra.py@gmail.com.

\section{Paul Smith} \\ Fundación Para La Tierra, Centro IDEAL, Mariscal Estigarribia 321 c/ Tte. Capurro, Pilar, Dpto. Neembucú, Paraguay \\ FAUNA Paraguay, Encarnación, Dpto. Itapúa, Paraguay www.faunaparaguay.com, faunaparaguay@ gmail.com
}

\section{Karina Atkinson}

Fundación Para La Tierra, Centro IDEAL, Mariscal Estigarribia 321 c/ Tte. Capurro, Pilar, Dpto. Neembucú, Paraguay

\begin{abstract}
We report data on the feeding preferences and behaviour of the little known didelphid Monodelphis (Mygalodelphys) kunsi, based on captive observations of a sub-adult female and a presumed sub-adult male. The behaviour observed is very similar to that documented for the better-known member of the genus, Monodelphis domestica. We confirm previously suspected prehensile tail use and tentatively suggest the species is insectivorous/carnivorous.
\end{abstract}

Key words: captive study, Cerrado, insectivore/ carnivore, pygmy short-tailed opossum

\section{Introduction}

The Pygmy Short-tailed Opossum Monodelphis (Mygalodelphys) kunsi Pine, 1975 is a small, little known didelphid opossum that is shrew-like in appearance (Anderson 1982; Pavan \& Voss 2016). Though it apparently has a wide distribution in eastern Bolivia (Tarija, Beni, Santa Cruz), northern Argentina (Salta), central Brazil (Tocantins, São Paulo, Goiás, Minas Gerais, Distrito Federal, Mato Grosso and Mato Grosso do Sul) and northern Paraguay (Canindeyú, Presidente Hayes and San Pedro), very few specimens are known (Astúa 2015; Pavan \& Voss 2016; Pavan et al. 2017). The species does not appear to have strict habitat requirements, being reported from Cerrado savanna (Mares et al. 1989), Chaco ravines (Salazar-Bravo et al. 1994), lowland Chaco scrub (De la Sancha et al. 2007), foothill Yungas (Jayat \& Miotti 2005) and semi-deciduous Cerrado gallery forest (Smith et al. 2012). Due to the wide distribution of the species, coupled with its occurrence in protected areas and resistance to habitat alteration it was downgraded from Endangered to Least Concern by the IUCN (Solari et al. 2015).

Monodelphis kunsi is the smallest species of the genus with a mean head-and-body length of $80 \mathrm{~mm}$ and mean weight of 11 $\mathrm{g}$ (Pavan 2015). It is brown in colouration with contrasting creamy-white venter pelage. Monodelphis kunsi has a small skull lacking a mid-sagittal crest (Anderson 1982). The dental formula of $M$. kunsi is unusual in having reduced canines (Anderson 1982, Jayat \& Miotti 2005). The ecology of the species remains almost entirely unknown and it is rarely captured in Sherman traps, but recently greater success has been achieved utilising pitfall traps (Cáceres et al. 2011; Hannibal et al. 2012). Anderson (1982) speculated that M. kunsi is carnivorous and possibly insectivorous though no data have been published about its diet and foraging habits (Anderson 1997, Astúa 2015). Monodelphis kunsi is known from just three widely spaced localities in Paraguay with specimens collected in Butia palm Cerrado at Aguara Ñu, Reserva del Bosque Mbaracayú, Canindeyú department (TK 67127 and TK 121105), lowland Chaco scrub at Cruce Los Pioneros, Presidente Hayes department (FMNH 164094) (De la Sancha et al. 2007), and sandy soil Cerrado and gallery forest at Rancho Laguna Blanca, San Pedro department (CZPLT 005, 215) (Smith et al. 2012).

The capture of two additional individuals at Rancho Laguna Blanca allowed captive behavioural observations to be made, and the results are detailed here.

\footnotetext{
Mammalogy Notes | Notas Mastozoológicas

Sociedad Colombiana de Mastozoología

Vol. 4 Num. 2| 2018
} 


\section{Artículos | Articles}

\section{Materials and methods}

Study area. Rancho Laguna Blanca (RNLB) $(-23.811485,-56.295984)$ is an 804 ha private property situated in north-eastern Paraguay (Figure 1), which was under legal protection between February 2010 and February 2015. It is surrounded by cattle ranches, and soybean and eucalyptus plantations. At the centre of the reserve is the eponymously-named 157 ha freshwater lake, geologically speaking, thought to be the only true lake in Paraguay (Guyra Paraguay 2008). The lake is low-nutrient with a sandy bed and surrounded by tall, wet grassy vegetation, sandy beaches and gallery forest. This transitional semideciduous, semi-humid gallery forest borders 400 ha of near pristine Cerrado. All four main Cerrado types are represented on the property and grow on a sandy substrate (Eiten 1972, 1978). A small patch of degraded Atlantic Forest is also present within the boundaries of the formerly protected area. The catchment area of the property, encompasses a total of 2449 ha and the courses of several rivers and streams including Río Aguaray Guasu, Rio Verde and Arroyo Clementina (Guyra Paraguay 2008). These waterways flood regularly in some areas to form extensive grassy marshes reminiscent of the vegetation of the Humid Chaco region.

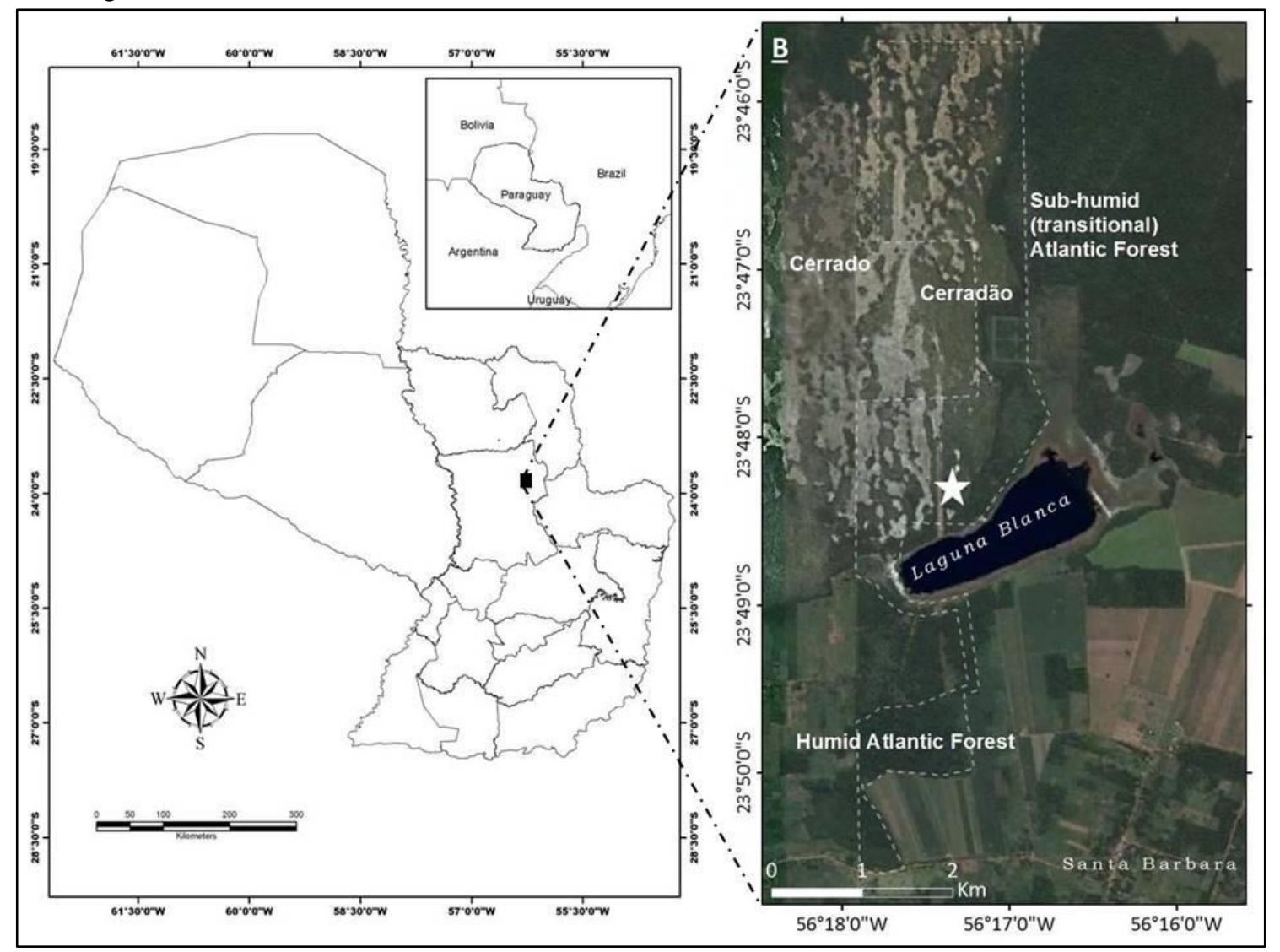

Figure 1. Capture sites of Monodelphis kunsi specimens A and B at Rancho Laguna Blanca (depicted by the star).

Individuals. A sub-adult female specimen (aged according to Pavan \& Voss (2016)) was captured on May 17, 2012 in a pitfall trap array in disturbed sensu stricto Cerrado $(-23.809944,-56.292111)$ and is henceforth referred to as Individual A. A male individual was then captured on $5^{\text {th }}$ April 2013 in grassy vegetation at the edge of the lake close to gallery forest, (-23.810472, -56.292111) and further observations were made on this individual; it is henceforth referred to as Individual B. The skull of Individual B was damaged during cleaning and it was not possible to establish the age class. However, based on comparison with the similar sized but slightly larger Individual A, it is assumed also to be a sub-adult (Table 1). Both individuals were taken into captivity temporarily and basic behavioural observations were recorded. Following their death both specimens were collected (CZPLT 234 and 431 respectively) under permits issued by the Secretaria del Medio Ambiente (SEAM). 
Table 1. Monodelphis kunsi specimen morphometrics and dental age class.

\begin{tabular}{ccccccc}
\hline $\begin{array}{c}\text { Specimen } \\
\text { CZPLT-(Individual) }\end{array}$ & $\begin{array}{c}\text { Capture } \\
\text { mass }(\mathbf{g})\end{array}$ & $\begin{array}{c}\text { Total length } \\
(\mathbf{m m})\end{array}$ & $\begin{array}{c}\text { Tail length } \\
(\mathbf{m m})\end{array}$ & $\begin{array}{c}\text { Hind foot } \\
\text { length }(\mathbf{m m})\end{array}$ & $\begin{array}{c}\text { Ear length } \\
(\mathbf{m m})\end{array}$ & $\begin{array}{c}\text { Dental age } \\
\text { class }\end{array}$ \\
\hline 234 (A) & 14 & 115 & 40 & 12 & 11 & $\begin{array}{c}\text { P3 present, } \\
\text { M4 not fully } \\
\text { erupted } \\
\text { Data } \\
\text { unavailable }\end{array}$ \\
431 (B) & 8.5 & 111 & 36 & 9.5 & 10 & $\begin{array}{c}10 \\
\text { und }\end{array}$ \\
\hline
\end{tabular}

Observations. The live individuals were housed in a plastic trunk $(88 \times 48 \times 40 \mathrm{~cm})$ with a sand and dead leaf substrate (imitating the ground where they were captured) and a mesh cover. Individual A was observed unsystematically from May 17 until June 7, 2012, for a total of 89 hours and 51 minutes. Individual B was observed for a total of 135 hours and 50 minutes between April 5, 2013 and May 2, 2013. Consequently, a total of 225 hours and 41 minutes of observations were carried out for both individuals. Notes were taken on behaviour during observation periods by a single observer (HP) on a natural daynight cycle. Nocturnal observations were carried out with a dim white light which had no discernible effect on behavioural patterns. Fresh water was available at all times. A variety of different animal and plant foods were offered and the animals' reactions to them noted.

Results

Activity levels. Both individuals were periodically active throughout the day and night, with clear crepuscular peaks of activity (Figure 2). They were docile; neither showed any aggression or attempts to bite the observer, even when handled. Individual B was initially timid on entering captivity and would hide from the observer. However, by Day 16 it was showing no reaction to disturbance and would resume normal behaviours immediately after the cleaning out of the enclosure. On Day 17 it began to actively approach the observer at feeding times.

Locomotion. Running was with the tail held out straight behind the body and snout parallel to the ground. They would often sniff at the ground or in the air when walking. Individual B was observed to run towards the edge of the enclosure with the head raised, standing up on the hind legs with the forefeet against the enclosure walls and the tail held perpendicular to the body (possibly offering support), occasionally shuffling along the sides of the enclosure in this position. It would sometimes jump from a distance of approximately $5 \mathrm{~cm}$ from the side of the enclosure, propelling itself with the hind legs and with the body adopting a "spread-eagl ed" position whilst in the air. It is presumed that both of these actions were attempts at escaping the enclosure, and whilst no climbing material was provided in the enclosure, it is assumed from these behaviours that they are capable of at least limited climbing. On one occasion a clumsy attempt was made to climb up a grass stem, this being too weak to bear the weight of the animal.

Possible Scent Marking. Male Individual B was seen to scratch the foreleg axilla using the hind leg. It then scratched the same area against the substrate by extending the foreleg, pressing the axilla against the ground and running in a straight line. It was observed to do this twice in succession and the behaviour was not observed again.

Foraging Behaviour. Live prey was only hunted when it was above the substrate (not buried) and movement often triggered a predation response; prey was pounced on and bitten on the body and head until it succumbed. The individuals often sniffed the air and motionless prey items, but rarely sniffed at the ground. They were seen to dig only on two separate occasions, adopting a position with the hind legs splayed and the face and both fore paws being forced into the sandy substrate, with sand reaching up to the eyes. On neither occasion did the individual successfully retrieve prey when digging. Prey was either eaten on the spot, or carried in the mouth, on all fours, to a corner of the enclosure for consumption. It was consumed whilst balancing on the hind legs, manipulating the prey with the fore paws. The subject fed prey into the side of its mouth, biting with its molars. Occasionally it would grip the body with its front teeth and yank its head back repeatedly to tear off manageable pieces.

\footnotetext{
Mammalogy Notes | Notas Mastozoológicas

Sociedad Colombiana de Mastozoología

Vol. 4 Num. 2| 2018
} 


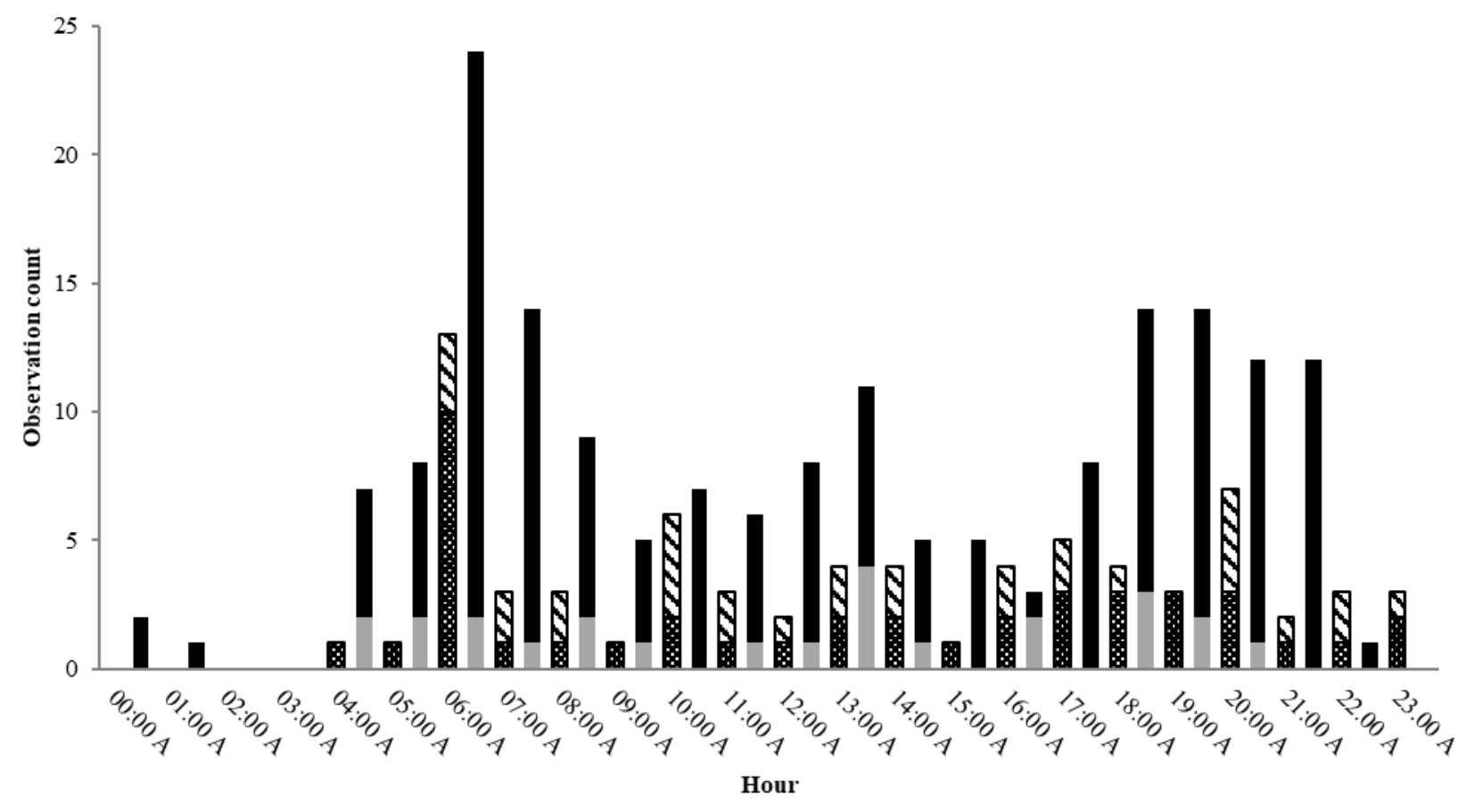

Specimen A Active $\boldsymbol{\square}$ Specimen A Awake $\quad$ Specimen B Active Specimen B Awake

Figure 2. Periods of activity, Monodelphis kunsi individuals A and B.

Reaction to invertebrate food. Different invertebrate taxa were handled in different ways:

Arachnida: Spiders (max length $30 \mathrm{~mm}$ ) were consumed head first, the forelegs being removed to provide access. Legs were consumed last, either at the same sitting or, on at least one occasion the individual discarded them only to return to later consume them. A scorpion Bothriurus sp. $(21.03 \mathrm{~mm})$ was offered to Individual B, which pinned the tail to the floor with the forepaw and dispatched it with a bite to the head. It was then consumed on the spot.

Blattaria: Native (Blaberus sp.) and introduced (Periplaneta americana) cockroaches (max length $33.50 \mathrm{~mm}$ ) were offered. Blaberus type (juveniles of which resemble woodlice in form) were consumed by holding the prey in the forelegs, feeding the insect into the side of the mouth and administering small bites around the outer part of the carapace, while discarding larger pieces of exoskeleton. The prey was continually rotated until the fleshy body could be accessed. $P$. americana were pounced upon with several bites being administered, before flipping the prey onto its dorsal side and biting off the head. The prey was then taken in the forefeet and similarly manipulated, with the fleshy parts of the body being consumed and the wings and harder parts of the exoskeleton discarded. On one occasion Individual B took several minutes to subdue a $P$. americana of $27 \mathrm{~mm}$ length, continually pursuing the insect and attempting to flip it onto its back. The killing blow was again delivered with a bite to the head after prising the legs away with the forepaws. Strips of flesh were removed by gripping with the teeth and pulling the head back to extract it.

Cicadidae: A small cicada Dorisiana drewseni $(21.20 \mathrm{~mm})$ was consumed, the wings discarded.

Coleoptera: Small beetles (up to $13.50 \mathrm{~mm}$ length) were consumed but a Scarabeid beetle cf. Deltochilum sp. of approximately $50 \mathrm{~mm}$ body length was ignored. Coleoptera were also regularly ignored when vertebrate prey was available and those capable of producing noxious substances were also rejected, in some cases after being first investigated.

Diplopoda: Millipedes of varying sizes were consistently ignored, perhaps because of the noxious secretions they produce. Lepidoptera: When it was able to catch them, it ate the body of Lepidopterans, discarding the wings. The largest specimens that were offered and consumed were an owl butterfly Caligo illioneus pampeiro (Nymphalidae: Morphinae) of body length $44 \mathrm{~mm}$ and a hawkmoth (Sphingidae) of body length $54 \mathrm{~mm}$. Individual B consumed a Saturniid moth

\section{Mammalogy Notes | Notas Mastozoológicas \\ Sociedad Colombiana de Mastozoología \\ Vol. 4 Num. 2| 2018}


(Adeloneivaia subangulata) in the typical way, holding the body in the forepaws with much flapping, and with rapid biting to the head to kill and consume it. This family of moths is known for the urticating hairs on the body of larvae and some adults. The M. kunsi paused regularly during consumption and was seen snuffling and sneezing repeatedly throughout, possibly suggesting discomfort. On one occasion when presented with an unidentified hairless green caterpillar, Individual B investigated it but rapidly pulled away appearing distressed, rubbing at the face with its forepaws and rubbing the face against the substrate. It then returned to the caterpillar with a similar result at which point it ignored it as potential prey. It was hypothesised that some kind of noxious secretion by the caterpillar may have been responsible. Mantodea: A mantid (43 mm) was consumed head first and the wings discarded.

Odonata: A dragonfly (49 $\mathrm{mm})$ was pounced upon and killed via bites to the head after a struggle. It was dragged around almost the entire perimeter of the enclosure and eaten in a corner. Again, it was consumed head first and the wings discarded.

Reaction to vertebrate food. Vertebrate prey offered was chosen based on abundance in the study area and availability during winter when the observations were taking place.

Reptiles and Amphibians: Small microteiid lizards Vanzosaura rubricauda Boulenger, $1902(\mathrm{SVL}=25.51 \pm 5.04 \mathrm{~mm}, \mathrm{n}$ = 38), Micrablepharus maximiliani Reinhardt and Lütken, $1862(\mathrm{SVL}=34.13 \pm 3.62 \mathrm{~mm}, \mathrm{n}=19)$ and Colobosaura modesta Reinhardt and Lütken, 1862 (SVL= $43.50 \pm 8.96 \mathrm{~mm}, \mathrm{n}=12$ ) (Gymnophthalmidae) were offered in the greatest quantities. Both M. maximiliani and V. rubricauda have been observed to flee from threats by taking refuge under leaf litter or rapidly burying themselves in sand, sometimes with just the detachable coloured tail remaining visible. Upon introduction into the container the $M$. kunsi would quickly pounce on the lizards before they were able to take defensive action and prey would be rapidly killed via a bite to the nape. However, lizards that were successfully able to bury themselves upon introduction were not pursued. Prey was held in the forepaws and the animal turned its head to feed the prey into alternate sides of the mouth, consuming it via a series of rapid chews. Vertebrates were consumed at the site of capture; head first, with the forelimbs and torso being eaten but the abdomen, hind legs and tail rejected at the first sitting. In many cases these remains would be consumed later, but no evidence of prey hoarding or hiding was observed. Two juvenile Teiid lizards (Teiidae) were also offered and taken: Ameivula abalosi Cabrera, 2012 (SVL = 35.19 mm, $\mathrm{n}$ =1) and Teius teyou Daudin, 1802 (SVL = $65.18 \mathrm{~mm}, \mathrm{n}=1)$. Amphibians: Small frogs Physalaemus cuvieri Fitzinger, $1826(\mathrm{SVL}=30 \mathrm{~mm}$ ) (Leiuperidae), and Adenomera diptyx Boettger, 1885 ( $\mathrm{SVL}=24.40 \mathrm{~mm}$ ) and Leptodactylus podicipinus $(\mathrm{SVL}=24.34 \mathrm{~mm}$ ) Cope, 1862 (Leptodactylidae) were offered as potential prey. Two larger frogs Eupemphix nattereri Steindachner, $1863(\mathrm{SVL}=39.48 \pm 10.49 \mathrm{n}=2)$ (Leiuperidae) were investigated (via sniffing) but later ignored. A small P. cuvieri was initially gripped in the forelegs and violently bitten to the dorsum and hind legs, before being manipulated in forefeet so it could be consumed head first.

Mammals: A juvenile mouse Akodon sp. (Cricetidae: Sigmodontinae) elicited no predation response. The two individuals later shared the same bedding area.

Reaction to vegetable food. A variety of different non-animal food was provided including carrot, green pepper, dried prunes, dried white grapes, other dried fruit, fresh banana, fresh tomato, corn kernels, apple, pear and a selection of different seasonally available wild fruits, flowers and leaves collected from the area where the specimens were trapped. Neither individual was observed to consume any of the material offered. Both specimens were also provided with "Opossum mix", which other captive Didelphids had readily consumed. This consisted of a hardboiled egg, a teaspoon of rare cooked chicken, sprinkling of milk powder, some bran flakes and less than $25 \%$ multivitamin and iron pill crushed mixed into a paste with some water. This was also refused by both individuals. Scrambled egg, raw egg in its shell and dog biscuits were offered to Individual B but also rejected.

Other dietary comments. Drinking by lapping from the water bowl was infrequently observed (Individual A n = 3, Individual B n = 3). Cooked meat (beef) and fish (cooked sardine) were refused, and dead vertebrates and invertebrates were ignored unless the animal had killed them itself and was returning to a partially finished meal. Individual A showed considerable

\footnotetext{
Mammalogy Notes | Notas Mastozoológicas

Sociedad Colombiana de Mastozoología

Vol. 4 N um. 2| 2018
} 
weight loss in captivity, declining in mass from $14 \mathrm{~g}$ to $9 \mathrm{~g}$ upon its death after 21 days, and losing $35.7 \%$ of its total body mass. Individual B CZPLT 431 increased in mass from $7 \mathrm{~g}$ to $10 \mathrm{~g}$ during its time in captivity, it subsequently lost weight and was recorded at $8.5 \mathrm{~g}$ upon death.

Despite rigorous trapping efforts over several years at this site all individuals have been captured in pitfall traps and none have been captured in Sherman traps baited with biscuits, vanilla essence and peanut butter.

Grooming and hygiene. After eating, both individuals were observed to groom the face by licking the plantar services of the forelegs and rubbing them over the head from just behind the ear to the nose in quick, repetitive movements. They were also observed to groom whilst lying on their sides in the nest, licking and nibbling at the feet and scratching the flanks.

On several occasions they were witnessed urinating (without cocking the leg) and defecating against the wall of the enclosure. When defecating, the animal squatted slightly with the tail raised away from the floor and the head in a forward position. The individuals also regularly defecated on their bedding. Faeces were vaguely torpedo-shaped, loose stools, dark brownish-black in colour and measured $4.5-5 \times 1-2 \mathrm{~mm}$.

Nesting and sleeping. A variety of potential nesting materials were provided over the course of the study including strips of newspaper $(2.5 \times 3,6,12$ and $24 \mathrm{~cm})$; strips of tissue paper $(9 \times 11.5$ and $23 \mathrm{~cm})$; stiff dry grass taken from the collection sites; short soft grass; toilet roll.

Nest building behaviour was never observed when the room temperature was above $18{ }^{\circ} \mathrm{C}$. Nesting material was picked up in the mouth. The animal then rose onto its hind legs and used the forefeet and the snout to push material towards the belly. Once achieved it then balanced on the forelegs and used the hind legs alternately (left and right) to push the material to the prehensile tail. Material was then gripped by curling the tail around it.

Nesting material was typically moved to a corner of the enclosure. The individuals were also observed to chew tissue paper, suggesting attempted manipulation of its properties. Once the material has been deposited in the nest the individual would continue to maintain the tail curled whilst doing other activities for a few minutes afterwards, even though it was holding no material. At all other times the tail was held extended.

Both individuals slept on their sides, curled into a ball with the tail curled around the head and forelimbs resting on the flanks. On rarer occasions they slept curled in a more "standing" posture with the head tucked between the forelimbs and the tail under the body. They would sleep either on top of the bedding material, or sometimes under it. The animal would pull nesting material towards it with the mouth when cold. On more than one occasion Individual B was found asleep on the exposed substrate.

\section{Discussion}

There are close parallels in some of the behaviours documented here with that of the better-known member of the genus, Monodelphis domestica. Scent-marking (Fadem \& Cole 1985), grooming (Macrini 2004), docility (Streilein 1982) and manipulation of nest material with the tail (Unger 1982) are all at least superficially similar. Streilein (1982) reported that $M$. domestica was predominantly nocturnal with peak activity occurring after dusk, whilst other species in the genus have been shown to be largely diurnal in behaviour, often with crepuscular peaks of activity (Charles-Dominique et al. 1981, Pine et al. 1985, Vieira \& Paise 2011, Astúa 2015). The data here suggest that $M$. kunsi is also somewhat crepuscular with limited activity throughout the day and night. Activity patterns in studied communities of small, insectivorous grassland mammals in the Neotropics are often temperature related, with cold nights avoided and canopy shade utilised during diurnal activity to remain active during the heat of the day (Vieira \& Paise 2011).

Though no discrete nest could be discerned by the observer, it seems that attempts to make a nest were made and it is possible that the material offered was insufficient for the purpose. Fadem \& Cole (1985) hypothesised that in M. domestica the elaborate procedure of transferring nest material from the mouth to the tail assisted in scent-marking the material by passing

\footnotetext{
Mammalogy Notes | Notas Mastozoológicas

Sociedad Colombiana de Mastozoología

Vol. 4 Num. 2| 2018
} 
it across the major scent glands. If this is true it seems unlikely that the similarly elaborate behaviours would be present in $M$. kunsi if no nest was subsequently intended.

The foraging behaviour described for M. domestica by Streilein (1982) identified similar manipulative skills to those witnessed in M. kunsi. These included the capture of flying insects, the pinning of the tail of a scorpion prior to killing it and the absolute attention given to the prey when eating. However, though Macrini (2004) noted that olfaction plays a major role in foraging in $M$. domestica, which "thrustsits nosethrough thesubstrate when searching for food", such behaviour was rare y observed in the captive individuals observed here, and a predation response was more often elicited by movement. Indeed, the defensive reaction of Gymnophtalmid lizards to bury themselves in sand seemed to be an effective way of avoiding predation. Both Teiidae species offered A. abalosi and T. teyou are abundant in the study area and employ a fleeing defence (Cacciali et al. 2016) and thus may have been handicapped by the small enclosure. It is questionable whether $M$ kunsi would be able to capture and consume adults of these species under natural conditions. It is not clear to what degree natural behaviours in both $M$. kunsi and prey species, were altered by captive conditions and the ready availability of food.

The limited data available on the diet of Monodelphis species concurs with the observations reported here in suggesting a mainly carnivorous/insectivorous diet (Bergallo \& Cerqueira 1994, González \& Claramunt 2000, Casella \& Cáceres 2006). Whilst the other sympatric members of the genus $M$. domestica and Monodelphis dimidiata readily consume vegetable matter (Unger 1982, Busch \& Kravetz 1991), M. kunsi consumed none of the fruit or plant matter that were available to it. The rejection of all vegetable matter and a largely visual method of prey detection may potentially contribute to the difficulty in capturing the species in Sherman traps.

Whilst suitable sized vertebrates were consumed instantly, it is of note that large insects were often left for some time before being eaten. Streilein (1982) noted that while $M$. domestica readily consumed lizards and frogs in captivity, in the wild they were primarily insectivorous. Wild observations are required to confirm whether the same may be true for $M$. kunsi.

The energy requirements of $M$. kunsi are very possibly higher than those met whilst feeding the subject on an insectivore dominant diet. Such a high energy demand may also provide a circumstantial explanation for the rapid weight loss and subsequent death of Individual A.

\section{Acknowledgments}

Thank you to the staff and volunteers at Para La Tierra Ecological Station for their hospitality and understanding during the period of this study. The Secretaria del Ambiente (SEAM) issued the relevant permits for the collection of the specimens. Thanks also to Malvina Duarte the owner of Laguna Blanca for her foresight and support of PLT, without which the fieldwork would not have been possible. PS and KA thank the PRONII program of CONACYT Paraguay for their support and commitment to the development of the sciences in Paraguay. Finally thank you to reviewers for their contribution and detailed critique of this paper.

\section{References}

ANDERSON, S. 1982. Monodelphis kunsi. Mammalian Species 190: 1-3.

ANDERSON, S. 1997. Mammals of Bolivia: Taxonomy and distribution. Bulletin of the American Museum of Natural History 231:1-652.

ASTÚA, D. 2015. Family Didelphidae (Opossums). Pp. 70-186 in Handbook of the Mammals of the World - Volume 5 - Monotremes and Marsupials (Wilson D. E. \& R. A. Mittermeier eds.), Lynx Edicions / Conservation International / IUCN, Barcelona.

BERGALLO, H. G. \& R. Cerqueira. 1994. Reproduction and growth of the opossum Monodelphis domestica (Mammalia: Didelphidae) in northeastern Brazil. Journal of Zoology, London 232:551-563.

BUSCH, M. \& F. O. KRAVETZ. 1991. Diet composition of Monodelphis dimidiata (Marsupialia, Didelphidae). Mammalia 55:619-648.

CACCIALI, P., et al. 2016. Observations on the escape behaviour in Teius oculatus and T. teyou (Reptilia: Squamata: Teiidae). Northwestern Journal of Zoology 12:151-158.

CÁCERES, N. C., et al. 2011. Differential trapping success for small mammals using pitfall and standard cage traps in a woodland savannah region of southwestern Brazil. Mammalia 75:45-52.

CASELLA, J. \& N. C. CÁCERES. 2006. Diet of four small mammal species from Atlantic forest patches in south Brazil. Neotropical Biology and Conservation 1:5-11.

CHARLES-DOMINIQUE, P., et al. 1981. Les mammifères frugivores arboricoles nocturnes d'une forêt guyannaise: inter-relations plantes-animaux. Revue d'Ecologie (La Terre et La Vie) 35:341-435.

DE LA SANCHA, N., et al. 2007. First records of Monodelphis kunsi Pine (Didelphimorphia, Didelphidae) from Paraguay, with an evaluation of its distribution. Mastozoologia Neotropical 14:241-247.

EITEN, G. 1972. The Cerrado vegetation of Brazil. Botanical Review 38:201-341.

EITEN, G. 1978. Delimitation of the Cerrado concept. Vegetatio 36:169-178.

FADEM, B. H. \& E. A. COLE. 1985. Scent-marking in the Grey Short-tailed Opossum (Monodelphis domestica). Animal Behaviour 33:730-738.

\section{Mammalogy Notes | Notas Mastozoológicas \\ Sociedad Colombiana de Mastozoología \\ Vol. 4 Num. 2| 2018}


GONZALEZ, E. M. \& S. CLARAMUNT. 2000. Behaviors of captive short-tailed opossums, Monodelphis dimidiata (Wagner, 1847) (Didelphimorphia, Didelphidae). Mammalia 64:271-285.

GUYRA PARAGUAY. 2008. Áreas importantes para la conservación de las aves del Paraguay. Guyra Paraguay, Asunción, Paraguay 470.

HANNIBAL, W., et al. 2012. New records of Monodelphis kunsi (Didelphimorphia, Didelphidae) from Brazil. Mastozoología Neotropical 19:317-320.

JAYAT, J. P. \& M. D. MIOTTI. 2005. Primer registro de Monodelphis kunsi (Didephimorphia, Didelphidae) para Argentina. Mastozoologia Neotropical 12:253-256.

MACRINI, T. E. 2004. Monodelphis domestica. Mammalian Species 760:1-8.

MARES, M. A., et al. 1989. Distribution and ecology of Cerrado mammals of central Brazil. Annals of the Carnegie Museum 58:1-60.

PAVAN, S. 2015. A new species of Monodelphis (Didelphimorphia: Didelphidae) from the Brazilian Atlantic Forest. American Museum Novitates 3832:1-15.

PAVAN, S. \& R. S. VOSS. 2016. A revised subgeneric classification of short-tailed opossums (Didelphidae: monodelphis). American Museum Novitates 3868:1-44.

PAVAN, S., et al. 2017. A new species of Monodelphis (Didelphimorphia: Didelphidae) from the Brazilian Amazon. American Museum Novitates 3872:1-20.

PINE, R. H. 1975. A new species of Monodelphis (Mammalia: Marsupialia: Didelphidae) from Bolivia. Mammalia 38:320-322.

PINE, R.H., et al. 1985. Ecology, postnatal development, morphometrics, and taxonomic status of the short-tailed opossum, Monodelphis dimidiata, an apparently semelparous annual marsupial. Annals of the Carnegie Museum 54:195-231.

SALAZAR-BRAVO, J. A., et al. 1994. New records of Bolivian mammals. Mammalia 58:125-130.

SMITH, P., et al. 2012. The Didelphimorphia (Didelphidae) of Reserva Natural Laguna Blanca, departamento San Pedro, Paraguay. Acta Zoológica Lilloana 56:141-153.

SOLARI, S., et al. 2015. Monodelphis kunsi. The IUCN Red List of Threatened Species 2015: e.T13696A22170540. Available from http://www.iucnredlist.org/details/full/13696/0 (Accessed online 25 October 2016).

STREILEIN, K. A. 1982. Ecology of small mammals in the semiarid Brazilian Caatinga I: Climate and faunal composition. Annals of the Carnegie Museum 51:79-107.

UNGER, K. L. 1982. Nest-building behavior of the Brazilian Bare-Tailed Opossum, Monodelphis domestica. Journal of Mammalogy 63:160-162.

VIEIRA, E.M. \& G. PAISE. 2011. Temporal niche overlap among insectivorous small mammals. Integrative Zoology 6:375-386. 